\title{
Optimization of Blast Furnace Throughput Based on Hearth Refractory Lining and Shell Thickness
}

\author{
Chinwuba Victor Ossia ${ }^{a^{*}}$, Uzoma Mathew Shedrack ${ }^{a}$ \\ aDepartment of Mechanical Engineering, University of Port Harcourt, Port Harcourt, Nigeria \\ *e-mail: chinwuba.ossia@uniport.edu.ng
}

(C) 2021 Authors. This is an open access publication, which can be used, distributed and reproduced in any medium according to the Creative Commons CC-BY 4.0 License requiring that the original work has been properly cited.

Received: 22 January 2021 /Accepted: 31 March 2021/ Published online: 15 April 2021

This article is published with open access at AGH University of Science and Technology Press

\begin{abstract}
Computational analyses were performed to optimize the furnace throughput, steel shell and lining thickness of a blast furnace. The computations were done for measured parameters within the hearth region as this is the vital zone of the furnace with high temperature fluctuations, molten iron, and slag production. The lining materials were namely $62 \%$ high alumina (A), carbon composite (B), silicon carbide (C) and graphite bricks (D) with thermal conductivities 2, 12, 120 and $135 \mathrm{~W} /(\mathrm{m} \cdot \mathrm{K})$, respectively. It was observed that by varying the refractory lining thickness from $0.2-0.35 \mathrm{~m}$, and furnace inside temperatures from 1873-2073 K, certain optimal conditions could be specified for the furnace under consideration. Silicon carbide and graphite brick linings which have higher thermal conductivities, melting points, good chemical and mechanical wear resistance were observed to be the best hearth lining materials. Due to the high thermal conductivities of these two materials, the hot face temperature levels of the lining materials would be lowered. Amongst the four lining materials employed, silicon carbide and graphite bricks when used with lining cooling systems could optimize the blast furnace for better performance, production, and longer campaigns.
\end{abstract}

\section{Keywords:}

hearth region, lining thickness, furnace optimization, chemical and mechanical wear resistance, longer campaigns

\section{INTRODUCTION}

\subsection{Background}

The blast furnace is the focus of any integrated steel plant. Blast furnaces are used to reduce iron ore (say, hematite $\mathrm{Fe}_{2} \mathrm{O}_{3}$ ) to wustite $(\mathrm{FeO})$ to molten pig iron ( $\mathrm{Fe}$ ). The raw materials consist of iron ore, pellets and/or sinter, coke, and flux (limestone and quartzite). Reducing conditions on account of gaseous reductants carbon monoxide (CO) and carbon dioxide $\left(\mathrm{CO}_{2}\right)$ enable this transformation.

Some blast furnace (BF) parts like the hearth, bosh, belly, stack, blast furnace stoves may require different quality of refractories depending on the requisite operating conditions and available resources. This study concentrates on the hearth region as a crucial zone subjected to high temperatures, heat and chemical interactions and production of slag and molten iron through the tapholes.

Selection of appropriate refractory combination in the hearth depends on in-depth knowledge of iron-making system and the physical, mechanical and chemical properties of the proposed refractories [1].

An improper understanding of the above factors often leads to refractory failures like wear which subsequently become complex problems to solve. Refractory linings, whether of a blast furnace or any other metallurgical furnace, usually fail due to any number or combination of such factors like improper furnace temperature distribution, high thermal expansion coefficients, lack of resistance to acid and alkali attack, etc.

This study deals with optimizing the furnace throughput and proper selection of refractory material of right insulation thickness. Four types of refractory lining materials, namely $62 \%$ high alumina $\mathrm{Al}_{2} \mathrm{O}_{3}$, carbon composite, silicon carbide (SiC) and graphite bricks, are examined to investigate the most suitable lining for optimum furnace performance.

\subsection{Blast Furnace}

The blast furnace is a vertical counter-current heat exchanger and chemical reactor for producing hot molten metal known as pig iron. In counter current manner, the ascending gas ( $\mathrm{CO}, \mathrm{CO}_{2}, \mathrm{H}_{2}$ and $\mathrm{N}_{2}$ ) flow and the permeable bed made up of iron ore, coke and flux descend. An illustration of the iron blast furnace is presented in Figure 1. The raw materials used in the process are coke, iron ore agglomerates of pellets or sinter and slag formers. Other materials that can be used are cold bonded briquettes, basic oxygen 
furnace slag and scrap. Alternating layers of coke, iron burden and slag formers are charged at the top. The material descends due to gravity when the coke is continuously burned at the tuyere level and the slag and molten pig iron (Fe) is tapped from the hearth $[2,3]$.

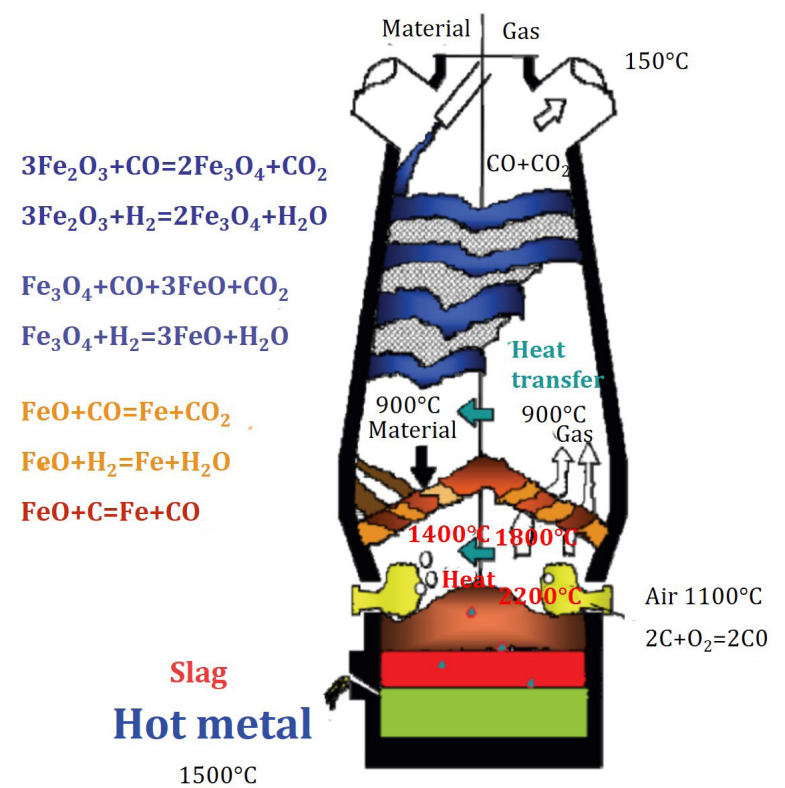

Fig. 1. Furnace cross section with the reactions at different heights [4]

The reduction of hematite to metallic iron occurs in different stages with different requirements on the reducing gas. To describe this, the carbon monoxide (CO) utilization factor, $\% \eta_{\mathrm{CO}}$, is introduced as expressed in Equation (1):

$$
\% \eta_{\mathrm{co}}=100 \% \cdot \frac{\% \mathrm{CO}_{2}}{\% \mathrm{CO}+\% \mathrm{CO}_{2}}
$$

Table 1 shows the different utilization factors and $\mathrm{CO} / \mathrm{CO}_{2}$ ratios at equilibrium for the reduction of the iron oxides at $900^{\circ} \mathrm{C}$. The reduction reactions given in Table 1 are called the indirect reduction of the iron oxides.

Table 1

$\mathrm{CO}$ utilization factors and $\mathrm{CO} / \mathrm{CO}_{2}$ ratios at equilibrium for iron oxides reduction at $900^{\circ} \mathrm{C}[1]$

\begin{tabular}{ccc}
\hline Reaction & CO/CO & \%ワCO \\
\hline $3 \mathrm{Fe}_{2} \mathrm{O}_{3}+\mathrm{CO}=2 \mathrm{Fe}_{3} \mathrm{O}_{4}+\mathrm{CO}_{2}$ & 0 & 100 \\
\hline $\mathrm{Fe}_{3} \mathrm{O}_{4}+\mathrm{CO}=3 \mathrm{FeO}+\mathrm{CO}_{2}$ & 0.25 & 80 \\
\hline $\mathrm{FeO}+\mathrm{CO}=\mathrm{Fe}+\mathrm{CO}_{2}$ & 2.3 & 30 \\
\hline
\end{tabular}

With reference to Table 1 , it is observed that at $900^{\circ} \mathrm{C}$ the required ratio to successfully reduce wüstite, $\mathrm{FeO}$, to metallic iron is 2.3 and the equilibrium reaction is as in Equation (2):

$$
\mathrm{FeO}+3.3 \mathrm{CO}=\mathrm{Fe}+\mathrm{CO}_{2}+2.3 \mathrm{CO}
$$

The counter-current outline of the process enables a gas rich in $\mathrm{CO}$ to come into contact with the wüstite $\mathrm{FeO}$. The gas is then successively depleted in CO while ascending in the furnace, reducing the iron oxides. An ideal temperature profile with the associated chemical reactions is depicted in Figure 2.

No single refractory material will satisfy the physical, chemical, and metallurgical demand of a blast furnace's operational demand. This work is devised to seek the right type of refractory material lining thickness and optimal shell thickness in the hearth region of a blast furnace for optimal throughput delivery. Table 2 shows the distribution and type of refractory lining in the different sections / zones of a blast furnace.

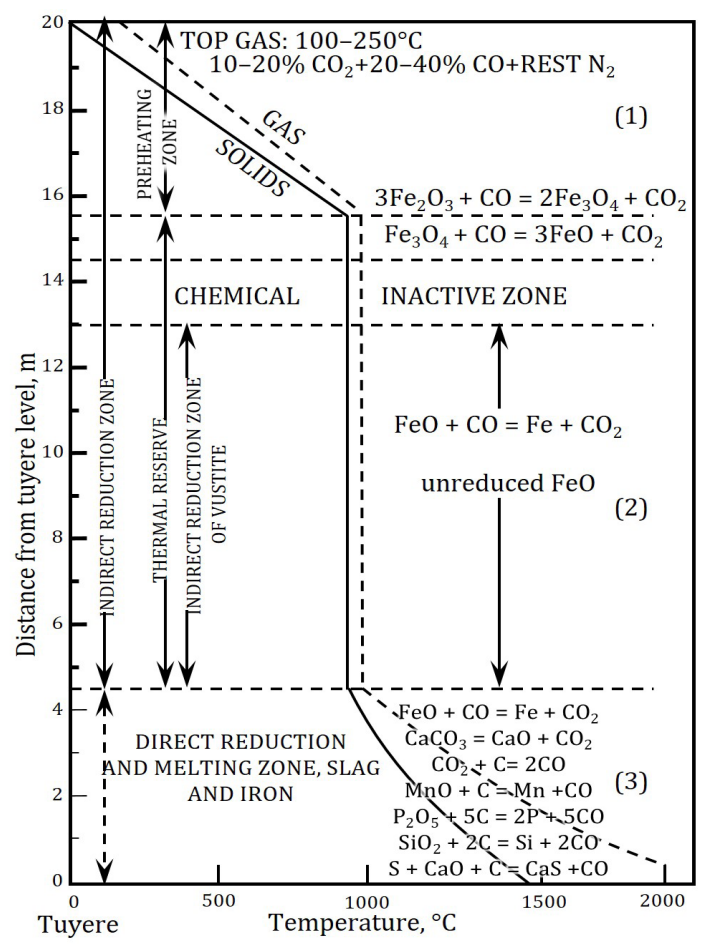

Fig. 2. Ideal temperature profile for the blast furnace represented as the height above tuyere level [1]

Table 2

\begin{tabular}{|c|c|c|}
\hline Area & $\begin{array}{c}\text { Refractory } \\
\text { nomenclature }\end{array}$ & Trend \\
\hline Stack & $39-42 \% \mathrm{Al}_{2} \mathrm{O}_{3}$ & super duty fireclay \\
\hline Belly & $39-42 \% \mathrm{Al}_{2} \mathrm{O}_{3}$ & corundum, SiC-Si3N4 \\
\hline Bosh & $62 \% \mathrm{Al}_{2} \mathrm{O}_{3}$, mullite & $\mathrm{SiC}-\mathrm{Si} 3 \mathrm{~N} 4$ \\
\hline Tuyere & $62 \% \mathrm{Al}_{2} \mathrm{O}_{3}$, mullite & $\begin{array}{l}\text { SiC self bonded, alumi- } \\
\text { na-chrome (corundum) }\end{array}$ \\
\hline Lower hearth & $\begin{array}{c}42-62 \% \mathrm{Al}_{2} \mathrm{O}_{3}, \text { mullite, } \\
\text { conventional } \\
\text { carbon block }\end{array}$ & $\begin{array}{l}\text { carbon/graphite block } \\
\text { with super micro pores }\end{array}$ \\
\hline Tap hole & $\begin{array}{l}\text { fireclay tar bonded, } \\
\text { high alumina / } \\
\text { SiC tar bonded }\end{array}$ & $\begin{array}{l}\text { fireclay tar bonded, high } \\
\text { alumina / SiC tar bonded }\end{array}$ \\
\hline Main trough & $\begin{array}{l}\text { pitch / water bonded } \\
\text { clay / grog / tar } \\
\text { bonded ramming } \\
\text { masses, castables }\end{array}$ & $\begin{array}{l}\text { ultra low cement } \\
\text { castables (ULCC), SiC / } \\
\text { alumina mixes, gunning } \\
\text { repairing technique }\end{array}$ \\
\hline Tilting spout & $\begin{array}{l}\text { high alumina / SiC } \\
\text { ramming masses / } \\
\text { low cement castables }\end{array}$ & $\begin{array}{l}\text { high alumina / SiC } \\
\text { / carbon / ULCC }\end{array}$ \\
\hline
\end{tabular}

Blast furnace refractory materials distribution 


\subsection{Blast Furnace Temperature Zones and Hearth Arrangement}

The blast furnace is comprised of different regions, namely: stack / shaft (19.0 m high), belly (2.5 m high), bosh ( $4.3 \mathrm{~m}$ high), hearth (6.2 $\mathrm{m}$ high) and the base region (4.8 $\mathrm{m}$ high) [5]. And the total blast furnace height under consideration is $28 \mathrm{~m}$. From Figure 3, the tuyere region has the maximum temperature of $2100^{\circ} \mathrm{C}$, while the hearth region showed $1500-1450^{\circ} \mathrm{C}$, bosh region $1000-600^{\circ} \mathrm{C}$, and while the shaft and belly region showed a temperature range of $600-200^{\circ} \mathrm{C}$ from the temperature contours in Figure 3.

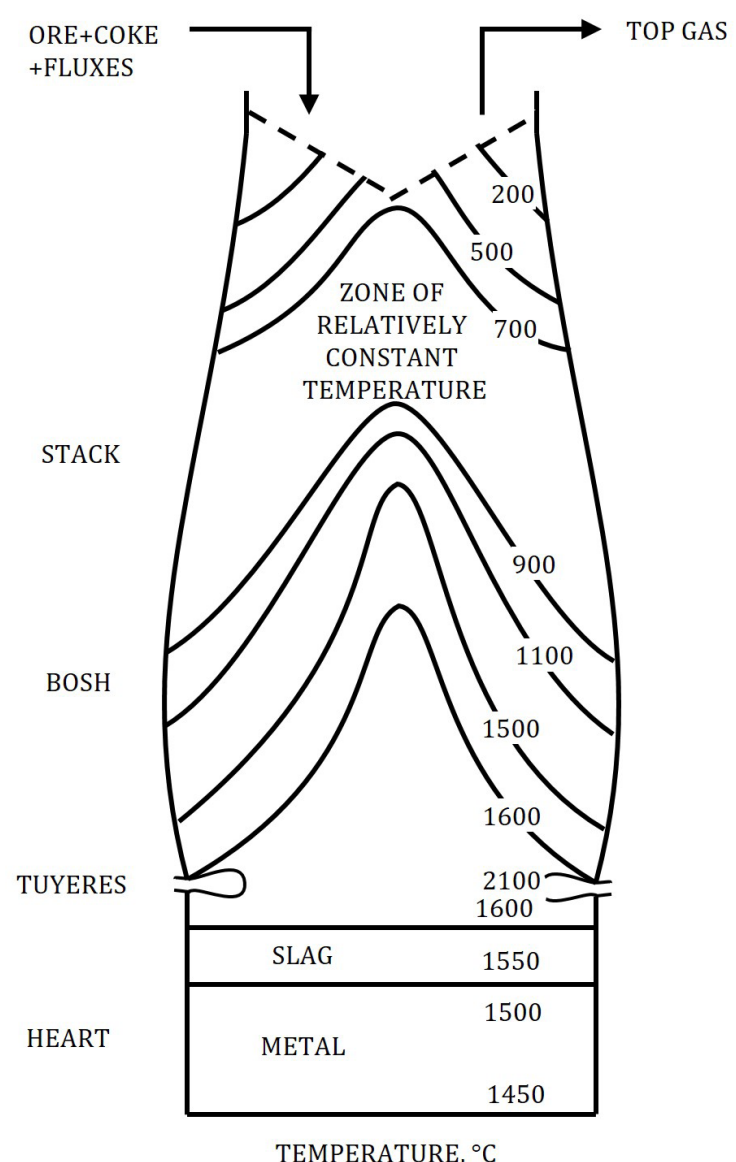

Fig. 3. Blast furnace temperature contours and the hearth region [6]

The furnace hearth is constructed by several refractory zones. The bottom part of Figure 4 (a) represents the dimension of the hearth under consideration. The taphole position is marked with the arrow line. The outside of the hearth is covered with a steel shell (a) in Figure 4. The wall and bottom are constructed from five types of refractory materials, each with its specific properties depending on what types of environment the region is exposed to. The wall (b) is made of any of the four lining materials under consideration $62 \%$ high alumina, carbon composite, silicon carbide and graphite bricks. They have low to relatively high heat conductivities to keep the inner wall at a low temperature. The upper layer of the bottom (c) is a ceramic plate with the composition $23.5 \% \mathrm{SiO}_{2}, 73.5 \% \mathrm{Al}_{2} \mathrm{O}_{3}$ and some additives. It has a high resistance to mechanical wear to keep the bottom layer intact and avoid cracks. That is important to avoid liquid iron penetrating and solidifying in the lower bottom layers (d), since this would have an impact on the heat flow. Between the steel shell and the bottom refractory is a layer of ramming paste (e). The blast furnace hearth is shown schematically in Figure 4. The taphole region in the hearth section shown in Figure 5 is made of a carbon refractory. It has very high heat conductivity to transport heat from the taphole during tapping and reduce the thermal stresses in the region.

The iron and steel industry is one of the key drivers of today's global economy. Efficient combustion and heat recuperation, recovery and conservation will improve pig iron production and this in turn will increase the economic and technological value of the furnace. Since the service life of the blast furnace depends largely on the state of the hearth lining and appropriate thickness, this research will aid the selection of better lining materials with superior properties and refractoriness.

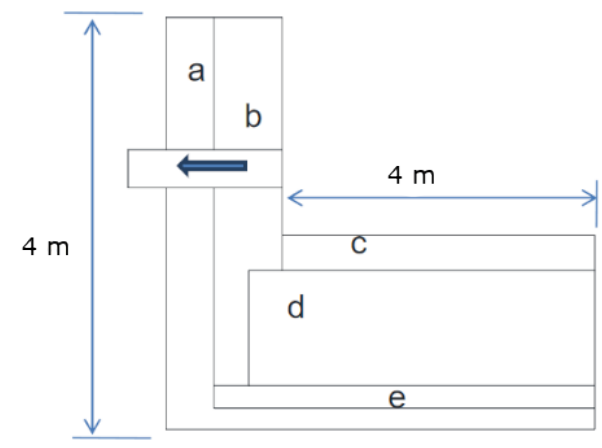

Fig. 4. Blast furnace hearth schematics - taphole is indicated by the thick arrow: a) steel shell; b) wall; c) upper layer of the bottom; d) the lower bottom layers; e) layer of ramming paste
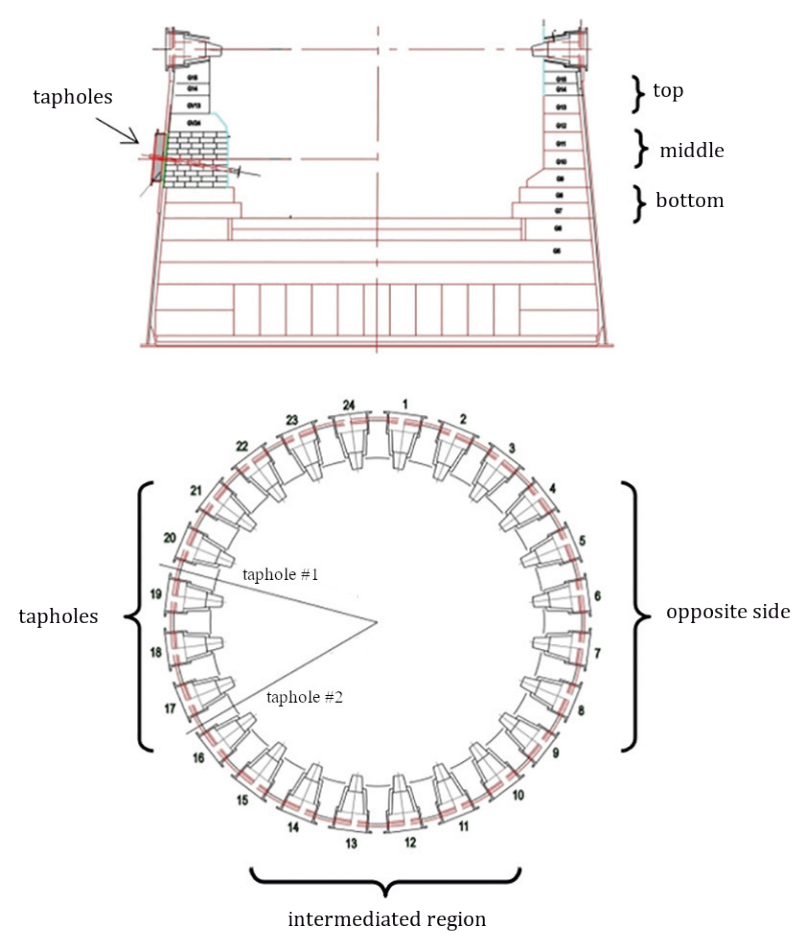

Fig. 5. Blast furnace hearth section [7] 


\section{MATERIAL AND METHOD}

\subsection{Hearth Lining Material Model}

Over the years, considerable efforts have been put on finding ways to increase blast furnace productivity and extend the campaign length. The state of the hearth has been identified as the most important factor by many for a long furnace campaign length. This lower region of the furnace is exposed to liquid iron and slag at high temperatures that could be in direct contact with the lining, causing erosion and corrosion of the lining material. The most aggressive environment is found in the region closest to the taphole. It is exposed to thermal stresses and liquid iron and slag at high flow rates [8].

Increased productivity results in higher loads on the furnace which can potentially shorten the campaign length. To strive to optimize both these goals, it is important to carefully control the state of the hearth. Most blast furnaces are equipped with thermocouples, measuring lining temperatures. Monitoring the information provided by the thermocouples can give instant information about the lining temperature, but also enable studies of the temperature evaluation on both a long-term and short-term basis $[4,9]$.

Accordingly, the ability to control the state of the hearth and maintain a steady operation, are two key issues in blast furnace practice. It is therefore of importance to understand the process and be able to interpret its behavior. The research aims to study the heat flows through the blast furnace hearth lining, compare four lining materials and their properties by numerical modeling to ascertain the best material for optimal throughput delivery.

The optimization approach entails varying the lining thickness from $0.2 \mathrm{~m}$ to $0.35 \mathrm{~m}$ and comparisons with respect to the heat loads developed. Similarly, the furnace hearth temperatures will be varied from $2073 \mathrm{~K}$ to $2673 \mathrm{~K}$ to achieve various values of the conduction heat loads for optimum performance and productivities.

\subsection{Model Formulation}

The following valid assumptions are made in the process of formulating the combustion and heat load analysis for the blast furnace for optimization:

- the analysis is done on a single layer refractory lining area with a one-directional profile as a case study,

- heat flow density $q$ in any location through the wall is constant,

- the models for the heat loads are derived at steady state; the implication being that no system parameter is time-dependent,

- the models developed subject to the fact that the furnace is very nearly cylindrical in structure. Based on the concept of the cylindrical coordinate system, the temperature at the center of the blast furnace is a maximum, but it is assumed to be the temperature at which solid iron changes to molten iron,
- the heat transfer at interfacial boundary zones is considered insignificant; hence the heat content of the different zones should be constant,

- optimization of the throughput and refractory lining will cover that of the steel shell, since the lining protects the shell from the high temperatures, chemical attacks and abrasive materials inside the furnace and most especially the high temperature hearth region; this simply means a suitable hearth lining material will enhance longevity of the steel shell in turn,

- the hearth space temperature is experimentally taken to be $1600^{\circ} \mathrm{C}(1873 \mathrm{~K})$,

- effects and compositions of the liquid metal and slag in the hearth region are neglected.

Technically, heat transfer analysis is one of the major studies employed to understand and enhance the performance of many metallurgical furnaces. Schematically, the temperature distribution through the walls of the hearth is as shown in Figure 6.

a)

b)
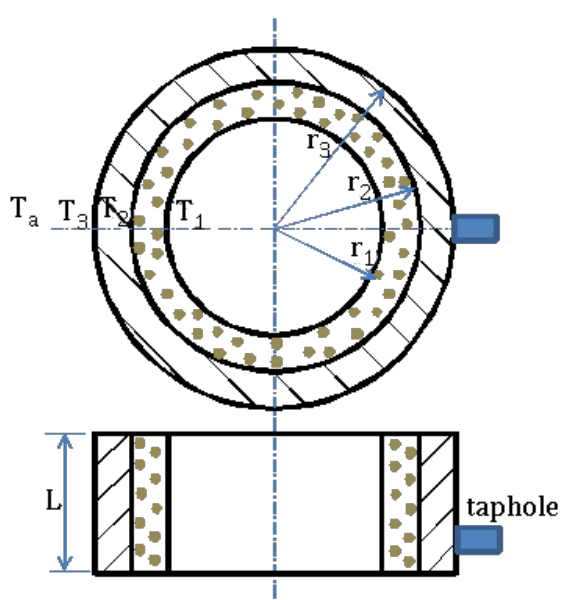

c)

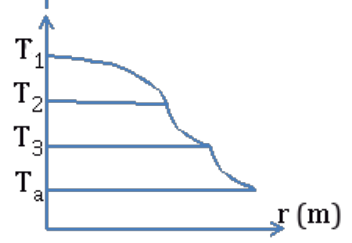

Fig. 6. Schematics and temperature profile of the hearth under study [3]: a) plan; b) elevation; c) temperature profile

Recall that Fourier's general law of heat conduction [10] can be expressed as Equation (3):

$$
Q=\frac{-k A\left(T_{2}-T_{1}\right)}{t}
$$

where: $t$ - thickness of the transfer medium (m).

The heat flux through the system - furnace workspace, lining and steel shell remains constant under steady state condition $[10,11]$. Hence, the radial heat flux $q_{r}$ is expressed as Equation (4):

$$
q_{r}=-k A_{r} \frac{\partial T}{\partial r}
$$

where: $A_{r}=2 \pi_{r L}$ 
Substituting gives Equation (5):

$$
q_{r}=-k 2 \pi r L \frac{\partial T}{\partial r}
$$

integrating both sides gives Equation (6):

$$
\int q_{r}\left[\frac{\partial r}{r}\right]=\int-k 2 \pi L \partial T
$$

inserting the limits of integration yields Equation (7):

$$
\int_{r_{1}}^{r_{2}} q_{r}\left[\frac{\partial r}{r}\right]=-k \int_{T_{1}}^{T_{2}} 2 \pi L \partial T
$$

this becomes Equation (8):

$$
q_{r} \ln \left[\frac{r_{2}}{r_{1}}\right]=k 2 \pi L\left(T_{1}-T_{2}\right)
$$

The heat flux $q_{l}$ through the inner lining with thermal conductivity $k_{l}$ can be given by Equation (9):

$$
q_{l}=\frac{2 \pi k_{l} L\left(T_{1}-T_{2}\right)}{\ln \left[\frac{r_{2}}{r_{1}}\right]}
$$

Similarly, the heat flux through the steel shell with thermal conductivity $k_{s s}$ can be given by Equation (10):

$$
q_{s s}=\frac{2 \pi k_{s s} L\left(T_{2}-T_{3}\right)}{\ln \left[\frac{r_{3}}{r_{2}}\right]}
$$

Similarly, the heat flux through the refractory material with thermal conductivity $k_{r m}$ can be given by Equation (11):

$$
q_{s s}=\frac{2 \pi k_{r m} L\left(T_{1}-T_{2}\right)}{\ln \left[\frac{r_{2}}{r_{1}}\right]}
$$

Let the convective heat transfer coefficient of the melt and the surrounding air be $h_{m}$ and $h_{\alpha^{\prime}}$ respectively. Heat transfer by convection, $q_{l m}$ to the internal surface of the furnace lining can be represented as Equation (12):

$$
q_{l m}=-h_{m} 2 \pi r_{1} L\left(T_{1}-T_{m}\right)
$$

The heat transfer rate from the surface of the steel shell to the surroundings by convection, $q_{s a}$ is expressed as Equation (13):

$$
q_{s a}=-h_{a} 2 \pi r_{2} L\left(T_{a}-T_{3}\right)
$$

Following similar arguments made by Briggs and Shedrack [3], and Gdula et al. [11], that under steady state conditions all conductive and convective heat flux must be equal, hence Equations (7)-(11) must be equal as in Equation (14):

$$
\begin{aligned}
q_{r} & =\frac{2 \pi k_{l} L\left(T_{1}-T_{2}\right)}{\ln \left[\frac{r_{2}}{r_{1}}\right]}=\frac{2 \pi k_{s s} L\left(T_{2}-T_{3}\right)}{\ln \left[\frac{r_{3}}{r_{2}}\right]}= \\
& =h_{m} 2 \pi r_{1} L\left(T_{m}-T_{1}\right)=h_{a} 2 \pi r_{2} L\left(T_{3}-T_{a}\right)
\end{aligned}
$$

\subsection{Furnace Input Data / Experimental Analysis}

All the heat load analyses, refractory material thickness and shell thickness calculations and simulations in this study were performed through the simulation subroutine in the Appendix, while its results were used to prepare the charts (figures) using sigmaPlot software

The furnace refractory lining materials thermal conduc-

\begin{tabular}{|c|c|c|}
\hline No. & Description & Value \\
\hline 1 & $\begin{array}{l}\text { daily furnace pro- } \\
\text { duction capacity } \\
\text { (THM/day) }\end{array}$ & 3000 \\
\hline 2 & $\begin{array}{c}\text { ambient temperature } \\
\left({ }^{\circ} \mathrm{C}\right)\end{array}$ & $28^{\circ} \mathrm{C}(301 \mathrm{~K})$ \\
\hline 3 & $\begin{array}{l}\text { refractory/shell } \\
\text { interface } \\
\text { temperature }\left({ }^{\circ} \mathrm{C}\right)(\mathrm{K})\end{array}$ & $45^{\circ} \mathrm{C}(318 \mathrm{~K})$ \\
\hline 4 & $\begin{array}{c}\text { hearth } \\
\text { temperature }\left({ }^{\circ} \mathrm{C}\right)(\mathrm{K}) \\
\end{array}$ & $1800^{\circ} \mathrm{C}(2073 \mathrm{~K})$ \\
\hline 5 & hearth area $\left(\mathrm{m}^{2}\right)$ & $3.5-6.5$ \\
\hline 6 & hearth height (m) & 4 \\
\hline 7 & hearth diameter $(\mathrm{m})$ & 9 \\
\hline 8 & $\begin{array}{l}\text { refractory ma- } \\
\text { terials used }\end{array}$ & $\begin{array}{l}\text { high alumina bricks, } \mathrm{Al}_{2} \mathrm{O}_{3}(62 \%), \\
\text { carbon composite bricks, silicon } \\
\text { carbide, } \mathrm{SiC} \text { and graphite }\end{array}$ \\
\hline 9 & $\begin{array}{l}\text { constant refractory } \\
\text { lining thickness }(\mathrm{m})\end{array}$ & 0.2 \\
\hline 10 & $\begin{array}{c}\text { blast furnace } \\
\text { working volume }\left(\mathrm{m}^{3}\right)\end{array}$ & 1339 \\
\hline 11 & number of tapholes & 2 \\
\hline 12 & number of tuyeres & 2 \\
\hline 13 & total weight (tons) & 9000 \\
\hline
\end{tabular}
tivity data used are shown in Table 3, while Table 4 outlines the characteristics of the blast furnace used in this study to investigate the best refractory material properties with constant and varied furnace temperatures, and lining thickness for the optimization process.

Table 3

Refractory materials thermal conductivities data

\begin{tabular}{ccc}
\hline Designation & $\begin{array}{c}\text { Refractory } \\
\text { material }\end{array}$ & $\begin{array}{c}\text { Thermal conductivities, } \\
\boldsymbol{k}(\mathbf{W} /(\mathbf{m} \cdot \mathbf{K}))\end{array}$ \\
\hline $\mathrm{A}$ & $\begin{array}{c}62 \% \text { high } \\
\text { alumina, } \mathrm{Al}_{2} \mathrm{O}_{3}\end{array}$ & 2 \\
$\mathrm{~B}$ & $\begin{array}{c}\text { carbon com- } \\
\text { posite bricks }\end{array}$ & 12 \\
\hline $\mathrm{C}$ & $\begin{array}{c}\text { silicon car- } \\
\text { bide, SiC }\end{array}$ & 120 \\
\hline $\mathrm{D}$ & graphite & 135 \\
\hline
\end{tabular}

Table 4

Experimental blast furnace data 
This work utilizes four different refractory lining materials, namely $62 \%$ high alumina $\left(\mathrm{Al}_{2} \mathrm{O}_{3}\right)$, carbon composite bricks, silicon carbide $(\mathrm{SiC})$ and graphite (labeled $\mathrm{A}, \mathrm{B}, \mathrm{C}$ and D), to investigate their roles in furnace optimization through heat interactions within hearth walls.

The lining thickness will be varied for each refractory material to illustrate the effect of an increased thickness on blast furnace productivity and the overall effect comparing each material listed. The same variation process will be applied to the hearth's interior temperatures.

Refractory lining materials will be considered individually to ascertain their heat handling characteristics and this will act as an indication as to the best material when considering the methods of optimization within the hearth region. Figure 7 shows the section of the experimental hearth zone and the various parts.

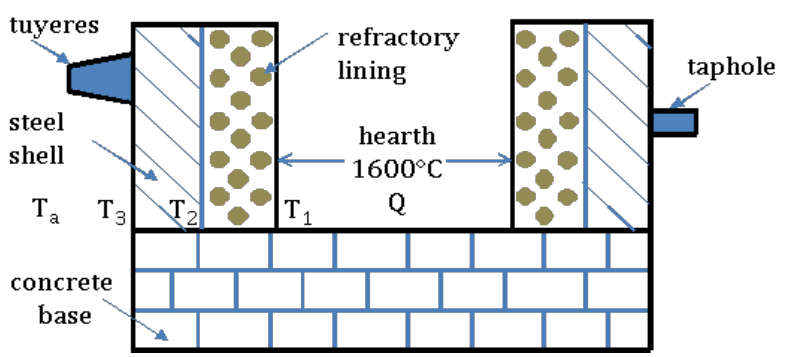

Fig. 7. A section of the hearth region under analysis

\section{RESULTS AND DISCUSSION}

\subsection{Effect of Hearth Refractory Materials}

Figures 8 and 9 confer on graphite the property of higher thermal load losses comparable to alumina, silicon carbide and carbon composite at hearth temperature of $1800^{\circ} \mathrm{C}$. On the basis of the optimal approach (Figs. 10 and 11), the optimal parameters for the refractory are as specified.

\section{Alumina}

Referring to Figure 10, at the optimal level of delivery, the thermal heat load is specified as $100 \mathrm{~kW}$ at $1600^{\circ} \mathrm{C}$ hearth temperature and $3.5 \mathrm{~m}^{2}$ surface area. The value of the shell thickness is $68 \mathrm{~mm}$ and the lining thickness variation is within the limit of $0.20 \mathrm{~m}$ to $0.35 \mathrm{~m}$.

\section{Carbon composite bricks}

The thermal heat load is $39 \mathrm{~kW}$, shell thickness is measurable as $70 \mathrm{~mm}$ to $74 \mathrm{~mm}$ and the lining thickness within the limit of $0.20 \mathrm{~m}$ to $0.35 \mathrm{~mm}$.

\section{Silicon carbide}

Optimally thermal load losses measured as $2200 \mathrm{~kW}$, shell and lining thicknesses being $100 \mathrm{~mm}$ and $0.285 \mathrm{~m}$, respectively.

\section{Graphite}

Graphite refractory exhibited the highest thermal load losses, with the numerical value fixed at $5450 \mathrm{~kW}$, shell thickness confirmed as $104 \mathrm{~mm}$ and the lining thickness being $0.287 \mathrm{~mm}$.
At hearth operating temperature of $1800^{\circ} \mathrm{C}$ and surface area $6.5 \mathrm{~m}^{2}$, the same trend was observed but with differences in the numerical values of the governing optimal parameter.

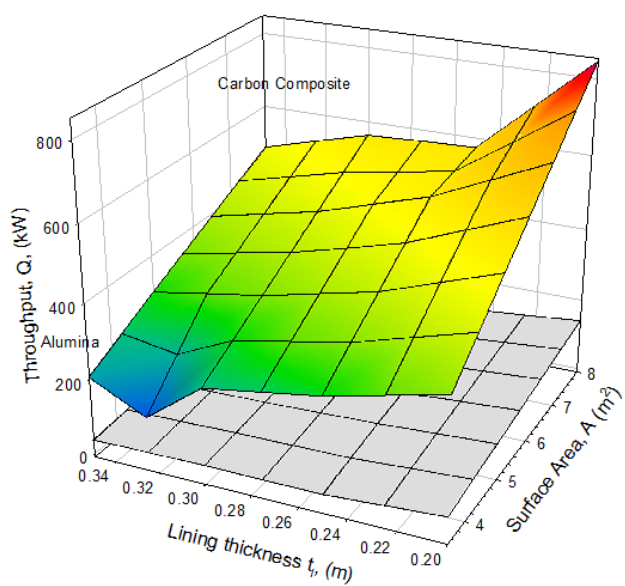

Fig. 8. Hearth throughput variation with lining thickness and surface area for alumina (gray) and carbon composite (colored) at $1800^{\circ} \mathrm{C}$

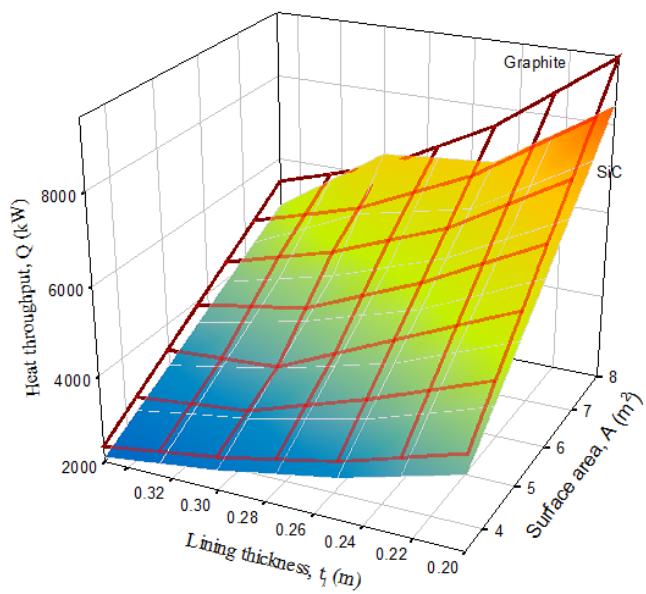

Fig. 9. Hearth throughput variation with lining thickness and surface area for graphite (red gridline) and silicon carbide (colored) at $1800^{\circ} \mathrm{C}$

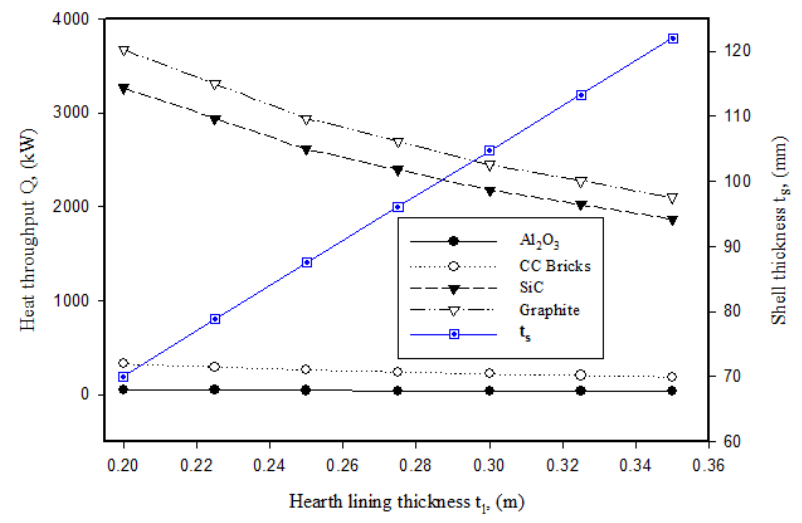

Fig. 10. Heat throughput $Q$ and shell thickness $t$ variation with lining thickness $t_{l}$ for different refractory materials at constant surface area $A=3.5 \mathrm{~m}^{2}, T=1600^{\circ} \mathrm{C}$ 


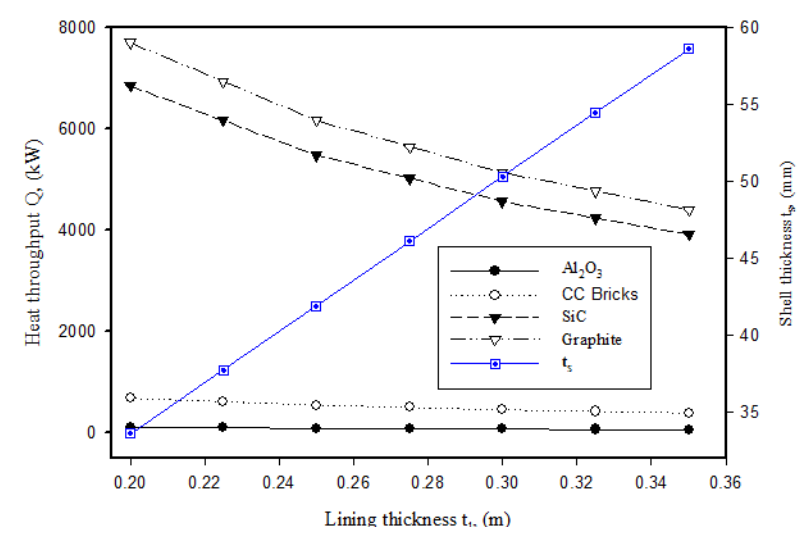

Fig. 11. Heat throughput $Q$ and shell thickness $t$ variation with lining thickness $t_{l}$ for different refractory materials at constant surface area $A=6.5 \mathrm{~m}^{2}, T=1800^{\circ} \mathrm{C}$

\subsection{Effect of Hearth Lining Thickness}

From Figures 8 and 9, it was observed that the thinner the hearth refractory lining thickness, the greater the thermal load losses from the system. To this effect, there is ever increasing attention to conserve heat in the hearth region of the blast furnace. This is to ensure excellent fluidity of the molten metal, for smooth and continuous production of the blast furnace; hence, the need for the optimization of refractory thickness in the hearth region.

\subsection{Effect of Temperature on Shell Thickness and Throughput}

For all the refractories (Figs. 12-14), shell thickness and lining thickness obey direct order but the reverse order to hearth temperature. The relationship of the shell and lining thickness to surface area of the hearth is of the inverse type. Subject to all observable conditions, the shell thicknesses at $1600^{\circ} \mathrm{C}$ is greater than that at $1800^{\circ} \mathrm{C}$. Hence the lower the hearth operating temperature, the thicker the shell thickness, although the conduction heat load losses is higher at higher hearth operating temperature. Saving in terms shell material should be juxtaposed with the thermal load losses in the hearth region to build an efficient blast furnace for iron ore refinement.

It is also worth noting that at constant lining thickness of $0.2 \mathrm{~m}$ for a different refractory, conduction heat load increases with increasing thermal conductivities of the refractory materials, while the shell thickness remains relatively constant at $0.0701 \mathrm{~m}$. This is an indication that a refractory with low thermal conductivity will lend itself to excessive heat conservation in the hearth region. Problems of wear, erosion and crack development and propagation and ultimate reduction in the campaign life of blast furnace are undesirable effects. For the variable lining thickness of each refractory, the same trend was observed but with distinct variability in the shell thickness. For $0.2 \mathrm{~m}$ to $0.35 \mathrm{~m}$ variability in lining, the shell thickness variation is the order of $0.0701 \mathrm{~m}$ to $0.122 \mathrm{~m}$ at $1600^{\circ} \mathrm{C}(1873 \mathrm{~K})$ temperature.

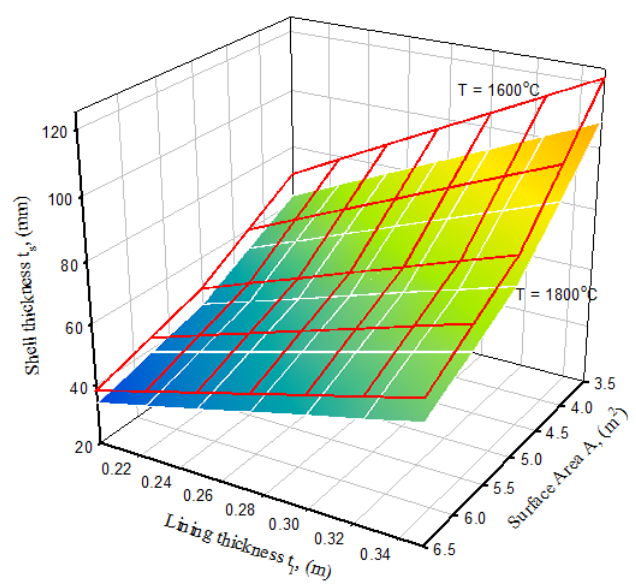

Fig. 12. Effect of temperature on hearth shell thickness $t_{s}$ variation with lining thickness $t_{1}$ and surface area $A$

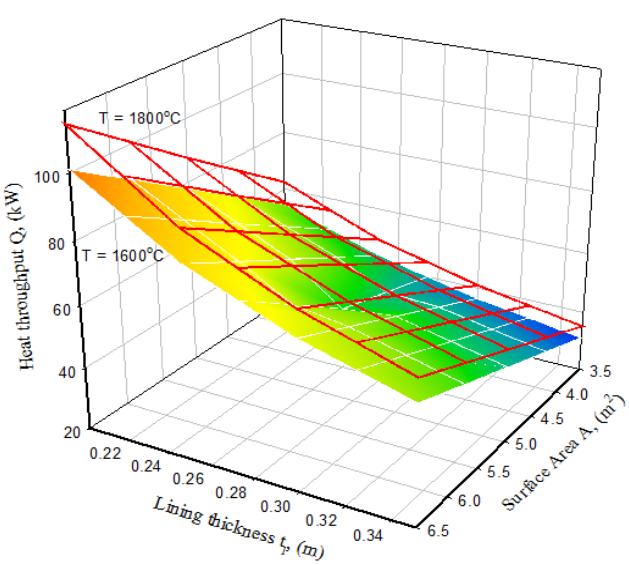

Fig. 13. Effect of temperature on heat throughput variation with hearth lining thickness and surface area of alumina refractory

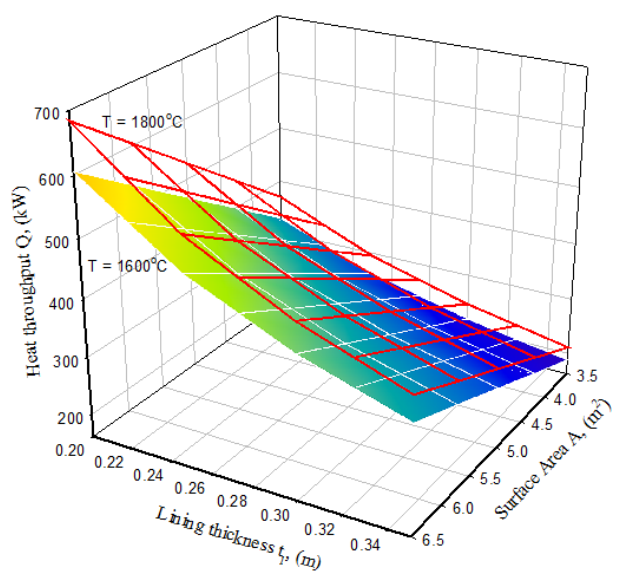

Fig. 14. Effect of temperature on heat throughput variation with hearth lining thickness and surface area of carbon composite bricks refractory

\subsection{Effect of Heart Surface Area}

Irrespective of the nature and type of refractories (Fig. 15), variation in shell thickness and lining thickness is in direct order while in the reverse manner to the surface area. 
Hence, the surface area is in inverse order, an indication of lower thermal load losses with increasing numerical order of shell thickness and refractory thickness.

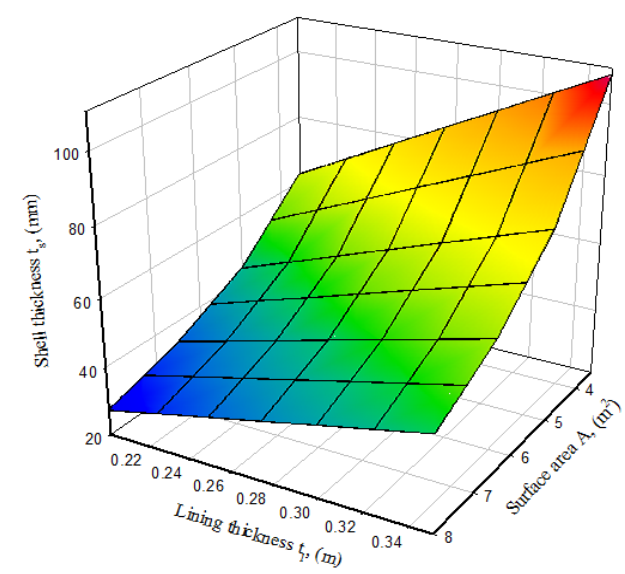

Fig. 15. Hearth shell thickness variation with lining thickness and surface area for all refractory materials at $1800^{\circ} \mathrm{C}$

\section{CONCLUSION}

The heat load consideration in the hearth region of the blast furnace and cooling system is of utmost importance since the wear reactions depend on the lining temperatures. This is all the more so as higher heat conductivity is a superior property in these regions of the blast furnace for three basic reasons:

- the lowering of the refractory hot face temperature to minimize chemical as well as mechanical wear,

- the resistance to temperature shocks is increased,

- the probability of forming a stable skull on the hot face is higher.

\section{REFERENCES}

[1] Biswas A.K. (1981). Principles of blast furnace ironmaking. Cootha: Brisbane, Australia.

[2] Hebel R., Steiger R. \& Streuber C. (1994). Advanced materials for the blast furnace lining in regard to long service life, reasonable cost and theoretical qualification. Proceedings of $53^{\text {rd }}$ Iron Making Conference, Chicago, March 20-23, AIME Iron and Steel Society, USA, 397-406.

[3] Briggs T.A. \& Uzoma S.M. (2019). Heat load analysis for optimal use of cupula furnace in iron castings and steel manufacturing. European Journal of Mechanical Engineering Research, 6(1), 32-43.

[4] Leimalm U. (2010). Interaction between Pellet Properties and Blast Furnace Operation. Luleå University of Technology, Luleå [Doctoral Thesis].

[5] Dutta S.K. \& Chokshi Y.B. (2020). Blast Furnance Process. In: Dutta S.K. \& Chokshi Y.B., Basic concepts of Iron and steel making, Springer, 51-68.

[6] Kumar D. (2015). Optimization of blast furnace parameters using artificial neural network. National Institute of Technology Rourkela-India [Masters Thesis].

[7] Lamont P.H. (1996). Synthetic carbon and graphite - a modern material for the future. Furnace and Refractory Engineer, Autumn, 7-11.

[8] Modigell M., Traebert A., Monheim P., Petersen S. \& Pickartz U. (2001). Anew tool for process modelling of metallurgical processes. Computers and Chemical Engineering, 25(4-6), 723-727. Doi: https://doi.org/10.1016/S0098-1354(01)00647-0.

[9] Bhagat P.K. (2015). Optimization of refractory lining used in blast furnace. National Institute of Technology Rourkela-India [Masters Thesis].

[10] Holman J.P. (1983) Heat transfer. Fifth Edition. McGraw-Hill International Book Company: New York.

[11] Gdula S.J., Białecki R., Kurpisz K., Nowak A. \& Sucheta A. (1985). Mathematical model of steady state heat transfer in the blast furnace hearth and bottom. Transactions ISIJ, 25, 380-385. 


\section{APPENDIX}

\section{Computer Simulation Subroutine}

\% CONDUCTION HEAT LOAD ANALYSIS, OPTIMAL REFRACTORY THICKNESS, DXr AND

은 THICKNESS, DXS FOR THE BLAST FURNACE

- AMBIENT TEMPERATURE, Ta $(K)$

$\mathrm{Ta}=301$;

FURNACE CENTER TEMPERATURE, T1 (K)

$\mathrm{T} 1=1873$;

TEMPERATURE AT REFRACTORY/SHELL INTERFACE, T2 (K)

$\mathrm{T} 2=318$;

disp( 'Kgra')

THERMAL CONDUCTIVITY OF 62\% ALUMINA REFRACTORY, Kal (W/mK)

응 $\mathrm{Kal}$;

o THERMAL CONDUCTIVITY OF CARBON COMPOSITE BRICK, KCCb (W/mK) $\mathrm{KCCl}=12$;

THERMAL CONDUCTIVITY OF SILICON CARBIDE REFRACTORY, KSC (W/mK) $\mathrm{KSC}=120$;

THERMAL CONDUCTIVITY OF GRAPHITE REFRACTORY, $\operatorname{Kgra~(W/mK)~}$ Kgra=135;

․ HEARTH RADIUS, r3 (m) $r 3=4.5$;

․ HEARTH LENGHT, L (m) $\mathrm{L}=4$;

for $A=3.5: 1.5: 12.5$

disp('A-Hearth Surface Area')

fprintf('⒛4f $\backslash n$ ', A)

\% HERATH SURFACE AREA, A(m2)

$A=3.5$;

ㄴ LET DXr (m) REPRESENTS THE THICKNESS OF THE REFRACTORY LINING for DXr $=0.2: 0.05: 0.35$

disp( 'DXr--Refractory Thickness') fprintf('⒛4f $\backslash n$ ', DXr)

ㅇ--is the conduction heat load in Watts

$\mathrm{Q}=\left(\operatorname{Kgra}{ }^{*} \mathrm{~A}^{*}(\mathrm{~T} 1-\mathrm{T} 2)\right) / \mathrm{DX} r$;

$\mathrm{q} 1=\left(2 * \mathrm{pi}{ }^{*} \operatorname{Kgra} \mathrm{L}^{*}(\mathrm{~T} 2-\mathrm{Ta})\right) / \mathrm{Q}$;

disp( 'q1')

$q 2=\exp (q 1)$;

disp( 'q2')

fprintf('2․10f $\backslash n$ ', q1,q2)

$r 2=r 3 / q 2$;

응 SHELL THICKNESS, DXS (m)

$\mathrm{DXs}=r 3-r 2$;

disp( 'DXs--Shell Thickness')

fprintf('⒛4f $\backslash n$ ', DXs)

disp('Q-Conduction Heat Load (Watts)')

fprintf('⒛4f $\backslash n ', Q)$

end

end 